\title{
Correction of an anterior crossbite in mixed dentition: a case report
}

Bationo $\mathbf{R}^{1}$., Ouedraogo $\mathrm{Y}^{2}$., Jordana $\mathrm{F}^{3}$.

1 Medical Center, General Aboubacar Sangoulé Lamizana Camp, Burkina Faso.

2 Health Department, University of Ouaga I Professor Joseph Ki-Zerbo, Yalgado Ouédraogo Teaching Hospital, Burkina Faso.

3 Department of Odontology, University of Nantes, Nantes Teaching Hospital, France.

\begin{abstract}
Anterior crossbite is a situation in which one or more maxillary incisors occlude lingually to their antagonists. It constitutes major esthetic and functional concern during the stages of dental development. Single tooth anterior crossbite is a commonly encountered malocclusion during the development of occlusion in children.

The correction of anterior crossbite requires the creation of enough space, to bring the displaced tooth or teeth across the occlusion into proper position.

Early treatment in very young children prevents the establishment of maloclusion that can potentialy worsen with age.

Different techniques have been used to correct anterior crossbite in mixed dentition. In this 8-year-old patient, a rapid maxillary expander with welded arm was used. This therapy combined with tonsillectomy followed by breathing exercises improved respiratory function.

It is therefore essential to intervene as early as possible to achieve the anatomical and physiological conditions for optimal of growth.
\end{abstract}

Keywords: anterior crossbite, rapid maxillary expansion, early treatment.

\section{INTRODUCTION}

In the mixed dentition, dental and alveolar abnormalies include premature loss of primary or permanent teeth, anterior dental crowding, agenesis, retained primary teeth, supernumerary teeth, alveolar insufficiency, open bite, over bite and crossbite.

Graber ${ }^{1}$ defined crossbite as a condition where one or more teeth may be abnormally malposed either lingually or labially with reference to opposing teeth. ${ }^{1}$ Anterior crossbite is a situation in which one or more maxillary incisors occlude lingually to their antagonists. $^{2}$

Factors such as palatal eruption of the maxillary incisors, trauma to the primary incisors, supernumerary anterior teeth, retained primary teeth, odontomas, crowding in the incisor region, and inadequate arch length have been implicated in the aehology of anterior crossbite. ${ }^{3-5}$

In the early mixed dentition, anterior and posterior crossbites are believed to be transferred from the primary to the permanent dentition and can have

\section{Correspondence: Dr Raoul Bationo}

Medical Center, General Aboubacar Sangoulé

Lamizana Camp, Burkina Faso

E-mail: raobat10@yahoo.fr

Received: $10 / 27 / 2017$

Accepted: 03/04/2018 long-term effects on the growth and development of the teeth and jaws. ${ }^{6}$

Anterior crossbite constitute a major esthetic and functional concern during the stages of dental development; when the purpose of an interceptive treatment is to normalize occlusion and create conditions for normal occlusal development.

Correction of anterior crossbite consists of labial tipping of upper incisors and lingual tipping of lower incisors.

Interception is a simple therapeutic procedure to achieve a partial or total correction before onset of full blown malocclusion. Its aim is to optimise anatomical and physiological conditions thus allowing normal growth to take place.

According to Salvadori ${ }^{7}$, interception makes it possible to prevent worsening of alveolar and skeletal disorders, thereby disrupting growth, function, aesthetics and sometimes the psyche of the child. This is achieved by correcting the malocclusion in the three dimensions of space, in order to restart the momentarily disturbed growth in its intensity or direction. $^{7}$

However, elimination of the abnormalities is an essential pre-requisite for treatment in mixed dentition. $^{8}$

Bassigny ${ }^{9}$ identified very early treatment in primary 
dentition, early treatment in mixed dentition and late treatment in adult dentition.

Early therapy will be short-lived and will involve simple methods. The devices used may have orthopedic or orthodontic action. The orthodontic treatment will most often be done after a period of suspension and supervision of varying duration.

This article documents a case in which an incisor cross bite was corrected using a rapid maxillary expander.

\section{Case report}

An 8-year-old female patient presented with anterior crossbite to the Department of Orthodontics of Pellegrin Teaching Hospital (Bordeaux). Clinical examination revealed the presence of mouth breathing with poorly developed nasal orifices and labial malocclusion at resting position with a lowered lip. There were also a slight palatal tipping of teeth 65 and 26 and single anterior incisor crossbite 11/41

Figure 1: Pre-treatment extraoral views
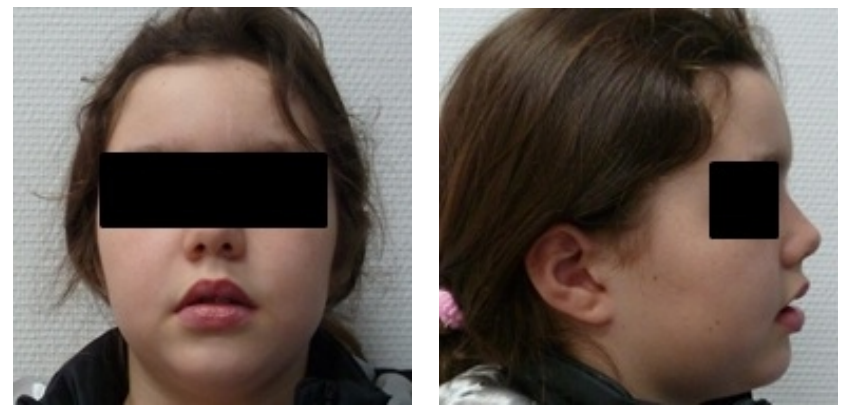

Figure 2: Pre-treatment intraoral views

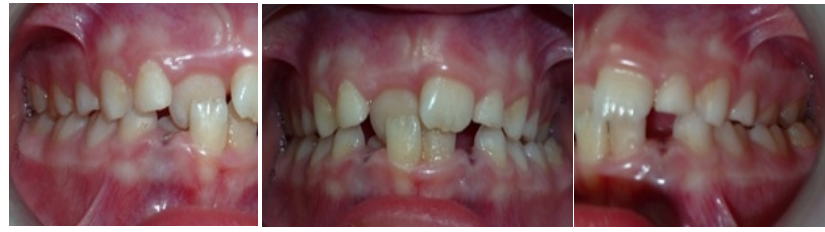

Panoramic radiograph showed normally developing permanent successor tooth germs (Figure 3).

\section{Figure 3: Panoramic radiograph}

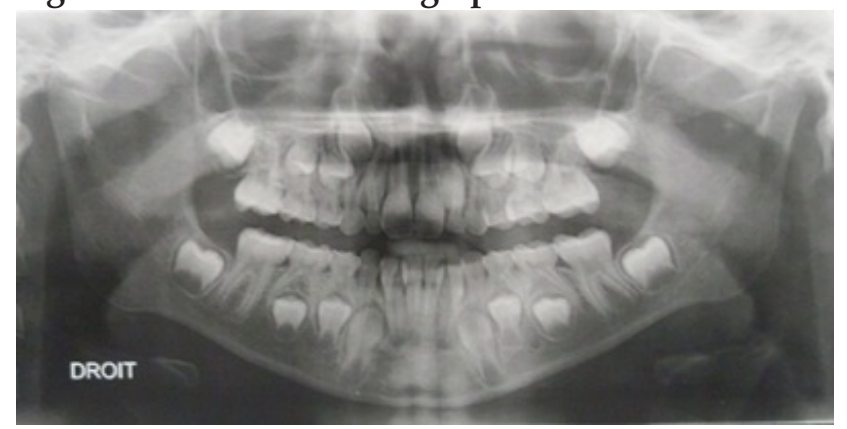

(Figures 1 and 2).

A voluminous tonsil appended to the palate was present on lateral cephalometric radiograph (Figure 4).

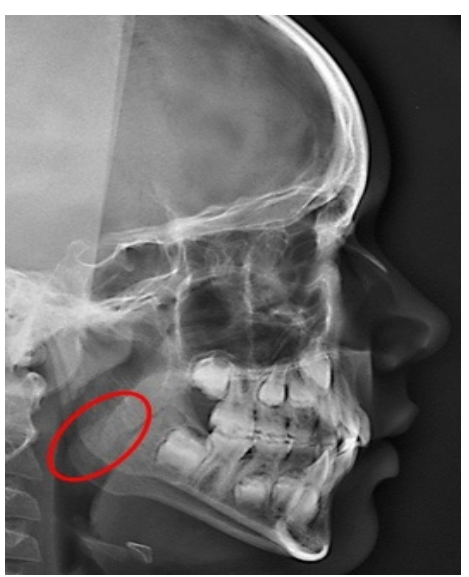

Figure 3: Lateral cephalometric radiograph

The nasopharyngeal obstruction required a tonsillectomy after ENT consultation followed by breathing exercises.

The early treatment was aimed at correcting dental and alveolar abnormalies and preventing future tooth size-arch length discrepancy. A rapid maxillary expander with welded arm (Figure 4) was cemented to the maxillary teeth and activated by a quarter turn twice a day for 7 days. The activation of the welded arm made it possible to tip labially the maxillary incisor. The correction of the incisor crossbite was achieved after 14 days. The rapid maxillary expander was then kept passive for one month.

Figure 4: Clinical views of the rapid maxillary expander and lingual arch
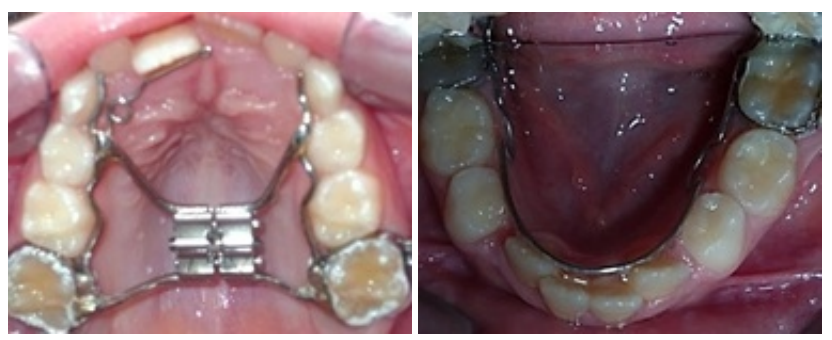

After a 3-month clinical monitoring, extractions of primary teeth $(52,62,73,83)$ were planned and a lingual arch with loops was set up to limit mandibular discrepancy.

Two years after treatment with maxillary expander, clinical observation indicated nasal breathing. The lips were competent at rest and a correction of initial abnormalies have been obtained. However, the over bite was exaggerated (Figures 5 and 6). 
Figure 5: Extraoral views after two years

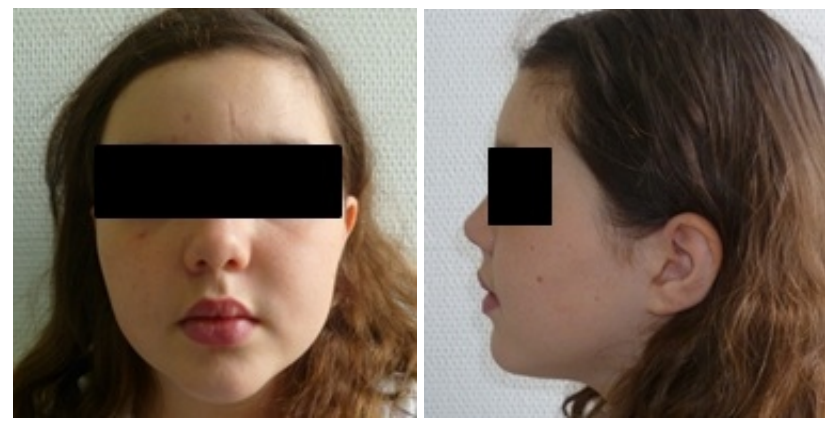

Figures 6: Intraoral views after two years

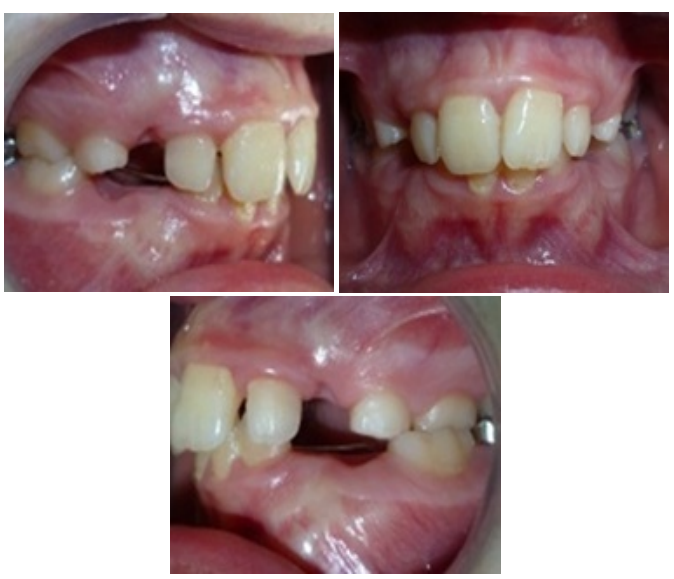

The lingual arch was planned to be maintained until the eruption of the lower premolars.

\section{Discussion}

The ideal age to treat anterior crossbite is between 8 years and 11 years, the period when the root is being formed and the tooth is in the active stage of eruption. ${ }_{10}$ The essential purpose interceptive orthodontics being arresting of bone or occlusal malformations in order to avoid complex treatment or to reduce treatment time.

In growing subject, interception should be considered mandatory in anterior and lateral crossbite, due to the direct action of the aggravating mechanisms, which inevitably makes the aggravation itself inevitable. On the other hand, interception becomes optional in the event of an increase in over bite, an over jet and anterior open bite. ${ }^{11}$

Different techniques have been used to correct anterior crossbite.

The tongue blade is the most basic technique, but it is rarely sufficient when more than one tooth is involved. ${ }^{12}$ The use of reversed stainless steel crowns presents some difficulties in adapting of a preformed crown to fit the tooth in crossbite and it is unaesthetic. ${ }^{13} \mathrm{~A}$ composite inclined plane is a simple and non-invasive effective technique but it cannot be used in cases where the anterior crossbite exceeds one third of the crown length. ${ }^{14}$ Removable orthodontic appliances are safe, easy and esthetically acceptable. ${ }^{15}$

Anterior crossbite involving one tooth, could have been corrected with a double helix apparatus. ${ }^{16}$

In our patient, because of mouth breathing, we have preferred the use of a rapid maxillary expander in order to obtain a slight enlargement of the floor of the nasal cavities, which will increase the nasal passage and facilitate nasal breathing. ${ }^{17}$

This transverse action induces, a reduction of the upper incisors malpositions and favors the spontaneous improvement of the respiratory functions. ${ }^{18}$ Anterior crossbite is one of the major responsibilities of pediatric dentist or orthodontist to guide the developing dentition to a state of normalcy in line with the stage of oro-facial growth and development. ${ }^{19}$

\section{References}

1. Graber TM. Orthodontics: Principles and Practice. 3rd ed. Philadelphia: W.B. Saunders, 1988.

2. Daskalogiannakis J. Glossary of orthodontic terms. 1st ed. Berlin: Quintessence, 2000.

3. Valentine F, Howitt JW. Implications of early anterior crossbite correction. ASDC J Dent Child 1970;37(5):420-427.

4. McEvoy SA. Rapid correction of a simple onetooth anterior crossbite due to an overretained primary incisor: clinical report. Pediatr Dent 1983; 5(4):280-282.

5. Bayrak S, Tunc ES. Treatment of anterior dental crossbite using bonded resincomposite slopes: case reports. Eur J Dent 2008; 2(4):303-306.

6. McNamara Jr JA. Early intervention in the transverse dimension: is it worth the effort? Am J Orthod Dentofacial Orthop 2002; 121(6):572-574.

7. Salvadori A. Avant-propos. Rev Orthop Dento Faciale 1987; 21:185-186 [in French].

8. Mauhourat S, Raberin M, Pernier C. Formes cliniques $\mathrm{du}$ déséquilibre musculaire en denture mixte. Conséquences morphogénétiques. Orthod Fr 2001; 72:83-99 [in French].

9. Bassigny F. Manuel d'orthopédie dento faciale. Paris, Masson. 1992 [in French]. 
10. Kiyak HA. Patients' and parents' expectations from early treatment. Am J Orthod Dentofacial Orthop 2006; 129(4Suppl):S50-54.

11. Tollaro I, Baccetti T. Propos sur les possibilités d'interception des malocclusions. Rev Orthop Dento Faciale 1996; 30:477-483 [in French].

12. Graber TM. Orthodontics Principles and Practice. 3th ed pp 673-675. Philedelphia: W.B. Saunders Company, 1972.

13. Croll TP. Correction of anterior tooth crossbite with bonded resin-composite slopes. Quintessence Int 1996;27:7-10.

14. Sari S, Gokalp H, Aras S. Correction of anterior dental crossbite with composite as an inclined plane. Int J Paediatr Dent 2001; 11:201-208.

15. Fields HW. Treatment of non-skeletal problems in preadolescent children. In: Proffit WR, editor. Contemporary Orthodontics. 4th ed pp 433-494. St. Louis,
Missouri: Elsevier, 2007.

16. Tanaka OM, Maciel JVB, Kreia TB, Ávila ALR, Pithon MM. The anterior dental crossbite: the paradigm of interception in orthodontics. Rev Clín Pesq Odontol 2010; 6(1):71-78.

17. De Coster T. L'expansion orthopédique du maxillaire. Orthod Fr 2006; 77:253-264 [in French].

18. Raberin M. Pathologies et thérapeutiques de la dimension transversale en denture mixte. Conséquences sur l'équilibre musculaire. Orthod Fr 2001; 72:131-142 [in French].

19. Al-Sehaibany F, White G. A three dimensional clinical approach for anterior crossbite treatment in early mixed dentition using an Ultrablock appliance: case report. Journal of Clinical Pediatric Dentistry 1998; 23(1):1-8. 